\title{
Propuesta de una Clasificación española sobre imágenes de pornografía infantil
}

\section{A proposal of a Spanish classification on images of child pornography}

Recibido el 22 junio 2016/Publicado el 5 abril 2017

\author{
Alejandra Pascual \\ Universidad Autónoma de Madrid
}

Andrea Giménez-Salinas ${ }^{1}$

Universidad Autónoma de Madrid

Carlos Igual

Dirección General Guardia Civil (España)

\begin{abstract}
RESUMEN
En la actualidad, el intercambio de material relacionado con la pornografía infantil ha aumentado considerablemente gracias al incremento de las oportunidades de difusión, las técnicas de producción así como las formas de intercambio y distribución del material en la red. La investigación policial sobre estos delitos se enfrenta a importantes retos, entre los cuales, destacan el volumen de casos de pornografía infantil que se detecta anualmente y la identificación de los perfiles de usuarios que potencialmente podrían convertirse en agresores sexuales. La investigación que se presenta en este artículo pretende contribuir a mejorar la eficacia policial en este ámbito, mediante el establecimiento de una clasificación nacional de imágenes y vídeos de pornografía infantil según la gravedad del contenido del material. Para ello, se han revisado una muestra de 4.116 fotografías y otra de 400 vídeos archivados en investigaciones realizadas entre 2008 y 2013 por la Unidad Técnica de policía Judicial de la Guardia Civil. Este artículo describe la clasificación escogida así como los niveles encontrados para las muestras analizadas, además de ofrecer la edad, el sexo y la etnia preferida por
\end{abstract}

\footnotetext{
${ }^{1}$ Autora de correspondencia: Andrea Giménez-Salinas Framis. Instituto de Ciencias Forenses y de la Seguridad. Universidad Autónoma de Madrid. Ciudad Universitaria Cantoblanco. C/Francisco Tomás y Valiente. 28049 Madrid (España). andrea.gimenezsalinas@inv.uam.es
} 
los consumidores en el material detectado. Finalmente, se presenta la validación de la clasificación a través de un acuerdo interjueces.

Palabras clave: Clasificación pornografía infantil, abuso sexual infantil.

\begin{abstract}
Nowadays, the interchange of child pornography material has grown considerably due to the increase of diffusion, production and interchange opportunities provided by Internet. Police investigations face significant challenges such as the big amount of child pornography cases detected annually and the identification of consumer profiles that may drive from child pornography to a real child sexual abuse. The goal of this research is to improve police efficacy in child pornography investigations with the establishment of a national scale of images and videos according to their content. For that purpose, we have revised a sample of 4.116 photographs and 400 videos identified among police investigations of Unit of Judicial Police of Guardia Civil from 2008 to 2013. This article presents the national scale and the more prevalent levels in the samples analysed. Additionally, the sex, age and ethnicity of images most consumed are presented. Finally, the scale has been evaluated by means of an inter-judge agreement.
\end{abstract}

Keywords: Child pornography scale, child sexual abuse

\title{
1. Introducción
}

La pornografía infantil, entendida como el material audiovisual en el que se utiliza a menores en un contexto sexual ${ }^{2}$, no es un fenómeno reciente. Hace bastantes años que se difunde contenido de pornografía infantil en distintos soportes y existe una porción todavía indeterminada de la población que demanda dichos contenidos. Sin embargo, tradicionalmente, estas imágenes se distribuían y consumían a través de papel o cintas de vídeo pero, con el nacimiento de Internet y la implantación de nuevas tecnologías, han aparecido nuevas formas y más rápidas de difusión que facilitan el consumo de imágenes de pornografía infantil (Morillas, 2005).

Las técnicas de producción y difusión del material pornográfico tradicionales han quedado superadas por las nuevas tecnologías y los dispositivos electrónicos actuales que ofrecen considerables ventajas: las imágenes se pueden visualizar, almacenar o modificar; y la difusión a través de Internet es generalmente gratuita, aparentemente anónima y de fácil acceso desde la privacidad del domicilio particular (Webb, Craissati

\footnotetext{
${ }^{2}$ Recomendación R(91)11 e Informe del Comité Europeo de Problemas Delictivos (1993).
} 
y Keen, 2007). Todas estas ventajas pueden encontrarse detrás del incremento del material disponible que también podría explicarse por el aumento del uso de internet entre los consumidores de pornografía infantil (Babchishin, Hanson y Hermann, 2011; Motivans y Kyckelhahn, 2007; Seto, Hanson y Babchishin, 2010; Wolak, Finkelhor y Mitchell, 2009).

Es difícil saber cuál es la causa del aumento del consumo de pornografía infantil, al igual que es complejo establecer estimaciones internacionales y nacionales fiables sobre el consumo e intercambio de este tipo de material en los diferentes países. En el ámbito europeo, el último anuario estadístico de criminalidad europeo (Sourcebook, 2014) no recoge el delito de pornografía infantil sino el de abuso sexual a menores. Debido a las dificultades para recoger cifras fiables acerca del delito de pornografía infantil, carecemos de datos que nos permitan conocer la envergadura de este fenómeno.

En el ámbito español, el último anuario estadístico publicado por el Ministerio del Interior (MIR, 2015), muestra que, en los últimos años, los delitos conocidos de pornografía de menores ${ }^{3}$ han sufrido un descenso hasta el año 2011 y un posterior repunte hasta el año 2015 (de 715 hechos conocidos en 2011 a 740 hechos conocidos en 2015). Esto puede deberse a que, desde hace unos años, ha aumentado la cantidad de material detectado por la policía, por lo que la prioridad policial se ha decantado por la investigación de los casos más graves (videos de menores de 13 años, ejerciendo conductas sexuales de especial gravedad y con repercusión internacional ${ }^{4}$ ).

La facilidad de producción y difusión de material pornográfico también implica un aumento en la comisión de delitos sexuales contra menores (Beech, Elliott, Birgden, A. y Findlater, 2008; Morillas, 2005; Taylor, Holland y Quayle, 2001a). Debemos tener en cuenta que detrás de cada imagen de pornografía infantil hay un niño que está siendo víctima de algún tipo de abuso sexual (Interpol 2003, citado en Sotoca 2010) . $^{5}$

Este aumento de la difusión de imágenes de pornografía infantil a través de la red supone una carga de trabajo importante para las fuerzas y cuerpos de seguridad que también deben lidiar con las dificultades que impone la investigación en el espacio digital. Como se ha comentado con anterioridad, a pesar de que en nuestro país, los

\footnotetext{
${ }^{3}$ El anuario estadístico del Ministerio del Interior 2013 recoge dentro de "pornografía de menores" los apartados 1, 2 y 7 del antiguo artículo 189 del Código Penal.

${ }^{4}$ Dicha afirmación sobre las prioridades policiales se ha obtenido de una entrevista con expertos policiales en investigaciones sobre pornografía infantil.

${ }^{5}$ Siempre y cuando no se trate de imágenes de pornografía infantil virtuales.
} 
recursos policiales se han orientado seriamente a la persecución de este tipo de delitos, la envergadura del fenómeno excede la capacidad policial ${ }^{6}$. Por este motivo, es imperioso acudir al diseño de herramientas que permitan aumentar la eficacia de las investigaciones y maximizar los recursos disponibles.

Este último argumento nos sirve para presentar el objetivo del presente artículo, que persigue presentar los resultados de una investigación realizada para la Unidad Central de Policía Judicial de la Guardia Civil que concluyó con la creación de una clasificación española de imágenes de pornografía infantil ${ }^{7}$. Por un lado, ésta clasificación podría servir de apoyo para las investigaciones policiales a la hora clasificar el material detectado, en función de la gravedad del contenido de las imágenes. Por otro lado, permitiría discriminar los casos más graves y asignar racionalmente los recursos de persecución disponibles. A lo largo de este artículo, presentaremos los resultados de esta investigación, explicando el proceso de generación de la clasificación nacional para el material recogido de pornografía infantil, así como su validación mediante un acuerdo interjueces. Para ello, inicialmente explicaremos el concepto de pornografía infantil así como las diferentes escalas existentes en el panorama internacional. Posteriormente, expondremos la metodología empleada para el estudio para abordar los siguientes resultados: la clasificación propiamente dicha, los niveles encontrados para la muestra analizada, las características de los menores (edad, sexo y etnia) que figuran en las imágenes detectadas y la validación interjueces de la clasificación.

\section{Concepto y clasificación de la pornografía infantil}

\section{1. Concepto de pornografía infantil}

Tradicionalmente, la pornografía infantil se ha considerado una exteriorización de otras tipologías delictivas como la explotación infantil o la trata de seres humanos (Morillas, 2005). Sin embargo, en la actualidad, aunque se reconoce que la pornografía infantil puede tener cabida dentro de las mencionadas tipologías delictivas, gran parte de las normas internacionales, la consideran y definen como tipología delictiva independiente.

\footnotetext{
${ }^{6}$ Información obtenida en entrevistas a expertos policiales dedicados a la investigación sobre pornografía infantil.

7 En este artículo nos referimos a imágenes pornografía infantil o explotación sexual infantil indistintamente, aunque entendemos que la terminología adecuada sería la de explotación sexual infantil.
} 
Este es el caso de la ley 25.763 del Protocolo facultativo de la Convención sobre los derechos del Niño ${ }^{8}$ de Naciones Unidas, la Decisión Marco 2004/68/JAI del Consejo de la Unión Europea ${ }^{9}$ relativa a la lucha contra la explotación sexual de los niños y la pornografía infantil; el Comité de Ministros del Consejo de Europa ${ }^{10}$, o la Convención del Consejo de Europa sobre Cibercriminalidad ${ }^{11}$, de 23 de Noviembre de 2001. Asimismo, cabe mencionar que el Código Penal español, con la reciente Ley Orgánica 1/2015 de 30 de Marzo, modifica el artículo 189 e introduce una definición de pornografía infantil $^{12}$ (hasta entonces inexistente) tomada de la Directiva 2011/93/UE.

Las definiciones legales que proporcionan estos instrumentos, aunque difieren unas de otras, tienden a enfatizar el contenido obsceno o sexual como una cualidad esencial de las imágenes de pornografía infantil (Taylor, Quayle y Holland, 2001b). Sin embargo, el contenido de las imágenes descargadas por los usuarios no se agota en esta tipología, hay otras imágenes que, aunque no cumplen los criterios de obscenidad y actividad sexual, se incluyen dentro del material erótico infantil porque también resultan de interés para los adultos (Taylor, 1999, citado en Taylor et al., 2001a). Por ello, para entender la pornografía infantil como fenómeno criminal, es necesario prestar atención a dos conceptos (Lanning, 1992): el de pornografía infantil, que incluye imágenes que representan una conducta explícitamente sexual y el de material erótico infantil, que incluye cualquier imagen de naturaleza sexual que, sin ser obscena o incluir actividades sexuales explícitas, puede ser utilizada con fines sexuales.

La distinción de estos conceptos resulta imprescindible para la comprensión del contenido pornográfico infantil y los perfiles de usuario, ya que únicamente el

\footnotetext{
${ }^{8}$ Toda representación por cualquier medio, de un niño dedicado a actividades sexuales explícitas, reales o simuladas, o toda representación de las partes genitales de un niño con fines primordialmente sexuales.

9 Cualquier material pornográfico que describa o represente de manera visual: i. a un niño real practicando o participando en una conducta sexualmente explícita, incluida la exhibición lasciva de los genitales o de la zona púbica de un niño, o ii. a una persona real que parezca ser un niño practicando o participando en la conducta mencionada en el inciso i) o iii. imágenes realistas de un niño inexistente practicando o participando en la conducta mencionada en el inciso i)"

${ }^{10}$ Todo material que muestre bien a un menor desarrollando una conducta sexual explícita, bien a una persona que aparentemente sea un menor desarrollando una conducta sexual explícita o bien represente imágenes realistas de un menor desarrollando una conducta sexual explícita.

11 Todo material pornográfico que represente: i. a un menor envuelto en un comportamiento sexual explícito. ii. Una persona aparentando ser menor envuelto en un comportamiento sexual explícito. iii. Imágenes realistas representando a un menor envuelto en un comportamiento sexual explícito.

12 "Todo material que represente de forma visual a una persona que parezca ser un menor participando en una conducta sexualmente explícita, real o simulada, o cualquier representación de los órganos sexuales de una persona que parezca ser un menor, con fines principalmente sexuales, salvo que la persona que parezca ser un menor resulte tener en realidad dieciocho años o más en el momento de obtenerse las imágenes".
} 
contenido objetivo no siempre permite entender y abarcar directamente todos los perfiles. También es importante tener en cuenta el impacto sexual que dichas imágenes tienen sobre el usuario. Por ejemplo, un contenido calificado como material erótico y sin actividad sexual explícita, puede inspirar una reacción sexual en el usuario igual de impactante que la actividad explícita. Por ello, en este tipo de intercambio de material, la dimensión objetiva y la subjetiva, se retroalimentan constituyendo un ciclo esencial para entender esta tipología delictiva.

A los efectos de nuestra investigación, hemos preferido escoger una definición que no estuviera ligada a una normativa concreta y que captara la esencia del concepto criminológico de pornografía infantil. Por otra parte, también incluimos en esta definición el concepto de pseudopornografía, preferentemente por dos razones: por la multitud de imágenes de este tipo aparecidas en la muestra y por la modificación reciente del artículo 189 del Código Penal español, que considera como pornografía infantil las imágenes realistas de un menor.

Así, la definición escogida de pornografía infantil para esta investigación es la siguiente: "toda representación, por cualquier medio, de imágenes reales o pseudoimágenes ${ }^{13}$ de un menor de 18 años ${ }^{14}$, dedicado a actividades sexuales explícitas, reales o simuladas, en las que se incluyen la representación de las partes genitales del menor e imágenes eróticas y sexualizadas"15.

\subsection{Necesidad de una clasificación que permita organizar el material de pornografía infantil}

La proliferación del intercambio de material pornográfico infantil ha supuesto un aumento en la detección e incautación de material de pornografía infantil que va acumulándose sin una clasificación u organización. En muchos países, se han elaborado

\footnotetext{
${ }^{13}$ Según Morales (2000, citado en Orts y Roig, 2009): “pseudopornografía” consiste en insertar fotogramas o imágenes de menores reales en escenas pornográficas en las que no intervienen realmente los menores, ya sea colocando la cara de un menor sobre la imagen de un adulto o añadiendo objetos a la imagen.

14 A efectos de considerar una imagen como pornografía infantil, se considera niño a las personas menores de 18 años porque en esta edad no se encuentran legalmente habilitados para consentir la participación en ningún tipo de explotación sexual incluyendo la pornografía infantil, con independencia de su edad de consentimiento sexual (International Centre for missing \& Exploited Children, 2012).

${ }^{15}$ Según el Proyecto de Informe sobre la sexualización de las niñas del Parlamento Europeo, se trata de la imposición de una sexualidad adulta a los niños que no se encuentran ni física, ni psicológica, ni emocionalmente preparados para ella en la fase de desarrollo en la que se encuentran.
} 
escalas que permiten clasificar el material pornográfico infantil con diferentes criterios: para medir la victimización infantil, para modular las penas impuestas a los usuarios, para mejorar la eficacia policial y asignar más eficazmente los recursos de investigación criminal. A continuación, describiremos las diferentes clasificaciones existentes para entender cómo hemos llegamos a elegir y adaptar una de ellas a nuestro contexto concreto. Previamente, explicaremos la utilidad de centrar las clasificaciones en el contenido y qué consecuencias operativas y científicas pueden derivarse de ello.

\section{¿Por qué centrarnos en el contenido de las imágenes?}

El contenido de las imágenes no tiene una importancia baladí, hay, como mínimo, tres circunstancias que convierten al contenido en una referencia clave en la descripción y seguimiento del fenómeno: el interés sexual provocado por el contenido, la posibilidad de identificar perfiles de usuarios según el material visualizado, y la victimización real que contiene el material visualizado.

En primer lugar, según hemos argumentado con anterioridad, el contenido objetivo de las imágenes está relacionado con el interés sexual del usuario. Quayle (2008) considera que algunos consumidores tienden a acumular grandes cantidades de imágenes de manera compulsiva con el fin de coleccionarlas o intercambiarlas con o sin ánimo de lucro. Sin embargo, los usuarios pueden ser selectivos en las imágenes que recolectan, por preferencias de edad, características físicas, sexo o actividades sexuales (Quayle y Taylor 2002; Quayle, 2008). Asimismo, el material visualizado puede producirse diferencialmente en función del interés sexual del usuario (Niveau, 2010; Quayle et al., 2002; Seto y Eke, 2005; Seto, Cantor y Blanchard, 2006). De todo ello se extrae que las colecciones de imágenes puedan mostrar las preferencias individuales por ciertas conductas sexuales. De esta manera, la personalidad del consumidor o información sobre su perfil criminológico de pornografía infantil podría inferirse del análisis del material consumido (Oswell, 2006).

Por otro lado, el consumidor o usuario persigue un efecto con las imágenes que dependerá de las características psicosociales del individuo. Del mismo modo, la gravedad de las imágenes contenidas en el material, podría también estar relacionada con un mayor interés sexual y una necesidad de escalar en el nivel de contenido disponible. Si existiera una escalada entre los usuarios que consumen material, de niveles inferiores de gravedad hasta los de mayor gravedad, podrían algunos de ellos 
pasar al abuso sexual infantil como forma de continuar su escalada ascendente. Esta diferencia entre consumidores y abusadores es realmente importante, no sólo para justificar una clasificación de material de pornografía infantil sino porque, desde el punto de vista criminológico, permitiría ahondar en el perfil y características de los consumidores de pornografía infantil. En estudios posteriores, derivados del contenido incorporado a la clasificación que da objeto a este artículo, podríamos diferenciar entre perfiles de consumidor, y averiguar si existen diferencias entre los que se quedan en el mero consumo de pornografía infantil y los que se convierten en abusadores infantiles (Babchishin et al., 2011; Webb et al., 2007; Bates y Metcaf, 2007).

Sobre esta cuestión todavía existe poca literatura y los estudios existentes no permiten llegar a conclusiones definitivas. Existen tres posturas divergentes en la literatura actual. La primera considera el consumo como un precedente del abuso sexual infantil. Quayle y Taylor (2001) defienden la existencia de una escalada ascendente desde la visualización de fotografías, vídeos y el posterior abuso sexual infantil. También Marshall (2000, citado en Warner, 2010), siendo menos contundente en su relación de causalidad, considera que la visualización de material pornográfico puede acelerar los procesos psicológicos favorecedores de distorsiones cognitivas en los consumidores. La segunda postura considera la visualización como un sustituto del abuso sexual (Riegel, 2004; Quayle et al., 2002), por lo que dicha visualización estaría evitando abusos reales. Por último, la tercera postura, niega la relación entre ambas conductas. Tanto Frei et al. (2005) como McCarthy (2010) o Endrass et al. (2009) consideran que el consumo de pornografía infantil, incluso la visualización del material más grave, no constituye un factor de riesgo para el abuso sexual posterior. A pesar de que todavía no exista evidencia suficiente para confirmar una relación directa entre consumo de pornografía infantil y abuso sexual posterior, es posible que los consumidores de pornografía infantil sean más propensos a buscar el contacto sexual con un niño que otros delincuentes sexuales (Seto et al., 2006). Por este motivo, algunos países europeos como Alemania ${ }^{16}$ y Reino Unido ${ }^{17}$ han desarrollado programas

16 The Prevention Project Dunkelfeld cosiste en un programa gratuito y confidencial dirigido principalmente a varones que sienten atracción sexual por menores o que consumen pornografía infantil. El objetivo es que aprendan a aceptar su preferencia sexual y hacerles conscientes de su problema para evitar, no solo el consumo de pornografía infantil, sino también la posibilidad de un abuso sexual posterior.

${ }^{17}$ El programa i-SOTP va dirigido a delincuentes varones adultos que han sido condenados por delitos como la descarga, posesión, producción o distribución de imágenes indecentes de niños. 
de prevención de abusos sexuales a menores que van dirigidos principalmente a pedófilos ${ }^{18}$.

Finalmente, las imágenes suelen contener, salvo en el caso de imágenes virtuales, victimizaciones reales de menores que incluyen abusos sexuales (Wolak, Finkelhor y Mitchell, 2011; Niveau, 2010; Quayle et al., 2002). Esta es la razón que promueve la inclusión de este tipo de conductas en los códigos penales nacionales, cuyo objetivo y finalidad es la protección del menor ante las imposiciones o coacciones de adultos. Por tanto, a mayor gravedad, mayor es la vulneración de derechos de los menores y más graves son las imposiciones a dichos menores.

\section{Utilidad de una clasificación de gravedad de las imágenes de pornografía infantil}

Atendiendo a las especificidades de la pornografía infantil comentadas con anterioridad, en ciertos países se han diseñado escalas o clasificaciones que permiten ordenar el contenido de estas imágenes. Éstas se han revelado útiles por tres razones. En primer lugar, porque consiguen ordenar la diversidad del material existente con el consiguiente beneficio para los policías implicados en las investigaciones criminales sobre pornografía infantil. Por otro lado, partir de un concepto más amplio de pornografía infantil y no vinculado especialmente al concepto legal, permite adscribirse a un criterio más homogéneo que puede ser comparable entre los países y no depender de las individualidades legislativas de los mismos (Taylor et al., 2001a). Finalmente, la segregación entre niveles de gravedad del material permite identificar las imágenes de mayor gravedad y estudiar el perfil de consumidores asociados. Ello puede favorecer la identificación de factores de riesgo asociados a dichos perfiles de gravedad y ayudar a identificarlos precozmente a partir de sus pautas de consumo y preferencias.

\subsection{Escalas internacionales del contenido de pornografía infantil}

Las escalas más conocidas a nivel internacional son: la escala del proyecto COPINE (Combating Peadophile Information Networks in Europe); la escala SAP (Sentencing Advisory Panel) y una tercera clasificación canadiense. A continuación, explicaremos brevemente el objetivo y finalidad de las mismas.

\footnotetext{
${ }^{18}$ El DSM V (Manual diagnóstico y estadístico de los trastornos mentales) en lo relativo a los trastornos sexuales y de la identidad sexual, contempla la pedofilia y la pederastia dentro del mismo diagnóstico, como "trastorno caracterizado por fantasías sexuales recurrentes y altamente excitantes, impulsos sexuales o comportamientos que implican actividad sexual con niños pre-púberes o niños algo mayores."
} 


\section{Escala COPINE}

Dicha escala se desarrolló en 1997 por el Departamento de Psicología de la Universidad de Cork en Irlanda, con la finalidad de categorizar la gravedad de las imágenes de abuso sexual infantil. Inicialmente, su finalidad fue únicamente terapéutica pero al final de los años 90 y, gracias a la colaboración de la Unidad de Pedofilia de la Policía metropolitana de Londres, se creó una tipología que servía tanto a profesionales como a investigadores policiales.

La escala, tal como se muestra en la tabla número 1, está dividida en diez niveles que atienden a la gravedad de la victimización del menor. El nivel 1 representa el nivel menos grave y el 10, el de mayor gravedad.

\section{Tabla 1.}

Niveles de la Escala COPINE

\begin{tabular}{|c|c|}
\hline Nivel & Descripción de la Victimización \\
\hline 1 & Indicativo: imágenes no eróticas y sin carácter sexual. \\
\hline 2 & $\begin{array}{l}\text { Nudista: imágenes de niños desnudos o semidesnudos en lugares apropiados y de } \\
\text { fuentes legítimas. }\end{array}$ \\
\hline 3 & Erótica: imágenes furtivas de niños desnudos o en ropa interior. \\
\hline 4 & $\begin{array}{l}\text { Poses: poses deliberadas de niños desnudos o semidesnudos, sugiriendo por el } \\
\text { contexto o la organización un interés sexual. }\end{array}$ \\
\hline 5 & Poses eróticas: poses sexuales o provocativas realizadas de forma deliberada. \\
\hline 6 & $\begin{array}{l}\text { Poses explícitamente eróticas: imágenes otorgando especial énfasis en los } \\
\text { genitales. }\end{array}$ \\
\hline 7 & $\begin{array}{l}\text { Actividad sexualmente explícita: imágenes de contenido sexual entre niños, sin la } \\
\text { participación de un adulto. }\end{array}$ \\
\hline 8 & Abuso: imágenes de actividades sexuales con la participación de un adulto. \\
\hline 9 & $\begin{array}{l}\text { Abuso extremo: imágenes de actividades sexuales con penetración incluyendo a un } \\
\text { adulto. }\end{array}$ \\
\hline 10 & $\begin{array}{l}\text { Sadismo y bestialismo: imágenes de actividad sexual que causan dolor o incluyen } \\
\text { animales que se encuentran implicados en actividades sexuales con el niño. }\end{array}$ \\
\hline
\end{tabular}

\section{Escala SAP}

La escala SAP se inspiró en la escala COPINE y se generó gracias al caso Regina contra Oliver en el Tribunal de apelación en Reino Unido (2002). Esta herramienta de clasificación se diseñó para que sirviera de apoyo a los jueces a la hora de decidir la pena a fijar en casos de pornografía infantil. La severidad de la pena se adopta, en estos casos, a partir de dos elementos principales: la naturaleza del material pornográfico y el alcance de la participación del autor. La Escala SAP consta de dos versiones. En su primera versión (2007) sufrió una adaptación a cinco niveles (Quayle, 2008) como muestra la tabla número 2. Los niveles en esta versión van del 1 al 5, siendo el 1 el de 
mínima gravedad y el 5 el de máxima gravedad. Las directrices para determinar las sentencias, teniendo en cuenta la escala SAP, se encuentran en una guía ${ }^{19}$ que orienta la determinación de las penas según los niveles de la clasificación.

\section{Tabla 2.}

Niveles de gravedad de las imágenes de la antigua Escala SAP

\begin{tabular}{|c|l|}
\hline Niveles & \multicolumn{1}{c|}{ Descripción } \\
\hline $\mathbf{1}$ & Imágenes que describen poses eróticas sin contenido sexual. \\
\hline $\mathbf{2}$ & $\begin{array}{l}\text { Imágenes conteniendo actividad sexual sin penetración entre niños o masturbación } \\
\text { entre niños o propia. }\end{array}$ \\
\hline $\mathbf{3}$ & Imágenes de actividad sexual sin penetración entre niños y adultos. \\
\hline $\mathbf{4}$ & Imágenes de actividad sexual con penetración entre niños y adultos. \\
\hline $\mathbf{5}$ & Imágenes de sadismo o bestialismo (penetración a o de un animal). \\
\hline
\end{tabular}

En 2013 la escala se redujo de 5 a 3 niveles para simplificar la determinación de las penas (tabla número 3). Este cambio se explica por dos razones: el máximo de condena en el Reino Unido por esta tipología delictiva es de 10 años y se advirtió que las colecciones de imágenes con frecuencia incluían imágenes mixtas, pertenecientes a más de un nivel.

\section{Tabla 3.}

Niveles de la nueva guía SAP

\begin{tabular}{|c|l|}
\hline Categoría & \multicolumn{1}{c|}{ Descripción } \\
\hline A & $\begin{array}{l}\text { Imágenes que incluyen actividad sexual con penetración y actividad sexual } \\
\text { sádica o bestialismo (antiguos niveles } 4 \text { y 5). }\end{array}$ \\
\hline B & Imágenes conteniendo actividad sexual sin penetración (antiguos niveles 2 y 3). \\
\hline C & Imágenes indecentes de niños. \\
\hline
\end{tabular}

Como consecuencia de la reducción de niveles, en la categoría A y en la categoría B no se distingue cuando la penetración se produce entre adultos y niños o entre niños.

\section{Clasificación de Canadá}

Por último, la escala más reciente se realizó en Canadá. Dicha escala consta de cuatro niveles aunque son más genéricos que las clasificaciones anteriores. La tabla número 4 recoge los cuatro niveles existentes, pero sólo el nivel 1 permite incluir material relevante para la pornografía infantil, el resto de niveles englobaría material que queda fuera de esta categoría.

\footnotetext{
19 The Crown Prosecution Service (January 2012). Sentencing manual. Indecent images of children. http://www.cps.gov.uk/legal/s_to_u/sentencing_manual/indecent_images_of_children/ 
Tabla 4.

Niveles de la escala de Canadá

\begin{tabular}{|c|l|}
\hline Niveles & \multicolumn{1}{|c|}{ Descripción } \\
\hline $\mathbf{1}$ & $\begin{array}{l}\text { Pornografia infantil: tal como se define en el Código Penal de Canadá. } \\
\text { Niños desnudos: imágenes de niños de naturaleza sexual, vestidos, desnudos o } \\
\text { semidesnudos, las cuales no se ajustan a las definiciones de pornografía infantil. }\end{array}$ \\
\hline $\mathbf{3}$ & $\begin{array}{l}\text { Otro material relevante: imágenes de niños que no realizan actos sexuales o que } \\
\text { no aparentan ser menores de 18 años. }\end{array}$ \\
\hline $\mathbf{4}$ & $\begin{array}{l}\text { Otro material: todas las demás imágenes que figuraban en los dispositivos } \\
\text { examinados. }\end{array}$ \\
\hline
\end{tabular}

\section{¿Por qué una clasificación distinta para nuestro país?}

La pornografía infantil es un fenómeno que está íntimamente ligado a factores de tipo cultural, creencias morales y pautas de comportamiento sexuales existentes en cada comunidad (Morales, 2002). Por este motivo, el equipo de investigación, formado también por personal de la Unidad de Pornografía de la Policía Judicial de la Guardia Civil, creyó conveniente crear una clasificación de pornografía infantil, tomando como referencia las escalas existentes a nivel internacional, pero adaptada al contexto español. Una vez revisadas las escalas se llegó a las siguientes decisiones, que permitieron generar el borrador de clasificación nacional:

El concepto de pornografía infantil que se tomó como referencia para la clasificación fue el presentado en el epígrafe sobre definición de pornografía infantil. Éste no se ciñe exclusivamente a la conducta definida por el Código Penal español porque, desde el punto de vista policial, se precisaba un concepto criminológico que recogiera las imágenes que presentaran un interés sexual para un adulto, aunque algunas no fueran ilegales.

La clasificación debía ser de utilidad para la investigación policial como herramienta de clasificación del material de pornografía intervenido en las distintas actuaciones policiales. Y, por otro lado, tener un interés científico que permitiera profundizar acerca de fenómeno: existencia de perfiles, tipologías de consumo, mejora de las estrategias de prevención y represión, etc.

\section{Método}

El principal objetivo del estudio era generar una clasificación nacional sobre el material de pornografía infantil. Para ello, se revisaron las clasificaciones de otros países, se adaptaron al contexto español y se generó una clasificación española. Ésta clasificación 
se aplicó a una muestra de fotografías y videos archivadas en investigaciones policiales realizadas entre 2008 y 2013 sobre pornografía infantil y, finalmente, se procedió a validar dicha clasificación a través de un acuerdo inter-jueces. Por otro lado, los resultados del estudio han permitido conseguir dos objetivos complementarios: describir, a partir de las muestras de imágenes y videos analizadas, los niveles más frecuentes de consumo de la escala, así como las preferencias de los usuarios, en función de la edad, el sexo y la etnia de los menores que protagonizan estas imágenes.

A continuación presentaremos el procedimiento utilizado para la aplicación de la clasificación a las muestras de imágenes de pornografía infantil:

\section{Primera visualización de la muestra de fotografías}

Una vez diseñada la clasificación generada para el contexto español debíamos comprobar que permitía clasificar todas las fotografías de forma inequívoca. Para ello se realizó una primera visualización de la muestra de fotografías $(\mathrm{N}=4116)^{20}$. Por otro lado, la propia configuración de las imágenes fijas o fotografías nos permitía conocer toda la variedad de posibilidades y acciones recogidas en el concepto de pornografía infantil. Esta primera visualización permitió clasificar las imágenes que fácilmente podían incluirse en los niveles existentes, quedando sin clasificar aquéllas que se encontraban entre dos niveles o resultaba difícil adscribirlas a un nivel determinado.

\section{Definición de la casuística integrada en cada uno de los niveles}

A medida que se visualizaban las fotografías, se anotaban las conductas que representaban cada una de ellas (a modo de etiqueta) para incluirlas en cada uno de los niveles escogidos. En referencia al etiquetamiento de las fotografías, debemos comentar que algunas de las fotografías de la muestra pertenecían a series consecutivas que iban de menor a mayor gravedad en las imágenes. En estos casos, se consideraron únicamente las fotografías individuales ya que el objetivo era encontrar la mayor casuística posible de contenidos para poderlos clasificar en los niveles de gravedad.

\section{Segunda visualización de la muestra de fotografías $(N=4116)$}

La segunda visualización se realizó con dos objetivos: verificar si todas las fotografías estaban bien clasificadas y ordenar aquellas imágenes que se habían quedado fuera en la

\footnotetext{
${ }^{20}$ Se empezó por las fotografías antes que los videos porque inicialmente se desconocía si sería necesario generar dos clasificaciones ajustadas a videos y a imágenes.
} 
primera visualización por no estar claro el nivel al que correspondían. Antes de proceder a la segunda visualización, se tomaron decisiones sobre cambios en la definición de niveles como consecuencia de la primera visualización.

Adaptación de la clasificación de fotografías a la muestra de videos disponible $(N=400)$

Una vez obtenida la clasificación definitiva para las fotografías, necesitábamos conocer si esta misma clasificación nos permitía incorporar el contenido de los videos o necesitábamos alguna adaptación para las imágenes en dicho formato. Los videos presentan una diferencia fundamental con respecto a las fotografías ya que incluyen distintas conductas a la vez, incluso una graduación de conductas desde las más leves a las más graves. Por este motivo, se decidió clasificar los videos atendiendo a la conducta más grave representada en ellos. El procedimiento para clasificar los videos fue el mismo que el utilizado para las fotografías (visualización y etiquetado).

\section{Clasificación definitiva para fotografías y vídeos}

La visualización de los vídeos permitió fácilmente clasificarlos en los niveles previstos para las fotografías, sin que aparecieran conductas distintas que requirieran una modificación. Por lo tanto, se decidió que la misma clasificación diseñada para las fotografías era válida para clasificar los videos.

\section{Resultados}

A continuación, presentamos los resultados obtenidos en la investigación realizada. En primer lugar, presentaremos la clasificación nacional definitiva para imágenes de pornografía infantil en el contexto español. Para ello, describiremos los niveles así como el contenido de las imágenes que debemos considerar en cada uno de ellos. Seguidamente, presentaremos los datos analizados después de haber clasificado la muestra de fotografías e imágenes: los niveles de consumo más frecuentes así como las características sociodemográficas de los niños que protagonizan las imágenes y los videos de pornografía infantil analizados. Finalmente, procederemos a exponer la validación realizada de la clasificación a través de un acuerdo interjueces. 


\title{
4.1. Clasificación de Imágenes de Explotación Sexual Infantil (CIESI)
}

La propuesta final de clasificación está basada en la antigua Escala SAP, aunque presenta algunas diferencias que comentaremos con posterioridad. Como se advierte en la tabla número 5, la clasificación consta de 6 niveles, siendo el 0 el de menor gravedad y el 5 el de mayor gravedad. A continuación, presentamos en la tabla número 5 los distintos niveles y su definición.

\section{Tabla 5.}

\section{Clasificación de imágenes de explotación sexual infantil}

\begin{abstract}
Nivel 0: otro material relevante
Imágenes que no se engloban dentro de la categoría de pornografía infantil: imágenes no eróticas y no sexualizadas de niños total o parcialmente vestidos o desnudos, provenientes de fuentes comerciales, álbumes familiares o fuentes legítimas, así como imágenes que no se pueden incluir en ninguno de los niveles superiores.
\end{abstract}

Nivel 1: desnudos o poses eróticas

Imágenes de niños total o parcialmente vestidos o desnudos, en poses provocativas o sexualizadas, o que hagan hincapié en las zonas genitales.

\begin{tabular}{|l|}
\hline Nivel 2: Actividad sexual entre niños \\
\hline${\text { Imágenes de actividad sexual }{ }^{21} \text { realizada entre niños o masturbación propia. }}^{\text {Nivel 3: Actividad sexual entre niños y adultos excluyendo la penetración de adulto a niño }}$ \\
\hline $\begin{array}{l}\text { Imágenes de actividad sexual con la participación de un adulto }{ }^{22} \text {. Se incluye la penetración } \\
\text { producida de niño a adulto pero se excluye la penetración (de cualquier tipo) de adulto a niño. }\end{array}$ \\
\hline
\end{tabular}

Nivel 4: Actividad sexual con penetración de adulto a niño

Imágenes de actividad sexual entre niños y adultos que incluyan penetración de adulto a niño.

Nivel 5: Actividad sexual sádica y bestialismo

Imágenes de actividades sexuales que aumenten el dolor físico o humillación de manera innecesaria, así como actividad sexual entre niños y animales.

El Nivel 0 es inexistente en otras escalas porque supone la ausencia de gravedad o de presencia de riesgo. Sin embargo, se recomendó incluirlo para introducir aquellas imágenes que no encajan en el concepto de pornografía pero quedarían archivadas con otros fines. En este nivel incluiríamos, por ejemplo, aquellas imágenes donde no es posible establecer la minoría de $\operatorname{edad}^{23}$ del protagonista o fotografías de niños desnudos

21 Tocamientos, caricias sexuales, contacto genital-genital, bucal-genital, genital-anal o bucal-anal. La
introducción de objetos sexuales por vía bucal también se considerará como penetración.
${ }_{22}^{22}$ La participación del adulto se entenderá como tal cuando se aprecie claramente su participación o
cuando exista algún miembro corporal del adulto que facilite o participe en la actividad sexual.
23 Siguiendo el artículo 8.2 del Protocolo facultativo de la Convención sobre Derechos del Niño relativo a
la venta de niños, prostitución infantil y la utilización de niños en la pornografía de Naciones Unidas, en
el caso de haber dudas acerca de la edad real del niño, no se debe impedir la iniciación de las
Revista Española de Investigación Criminológica
15

Artículo 1, Número 15 (2017)

WwW.criminologia.net

ISSN: 1696-9219 
tomadas en la playa o piscina que no hacen hincapié en los genitales; imágenes borrosas, o imágenes en las que únicamente aparece el rostro del niño.

En el Nivel 1 se introducirían aquellas imágenes en las que el contexto $\mathrm{u}$ organización de la imagen suscita un interés sexual (niñas con ropa interior de mujer adulta o niños sin poses eróticas sosteniendo juguetes sexuales); imágenes que se centran en las zonas genitales, así como aquellas imágenes donde se describen poses provocativas o están mostrando explícitamente los genitales.

El Nivel 2 incluye las imágenes que incorporan una actividad sexual entre niños y, al igual que lo hace la escala SAP, no se distingue entre actividad sexual con o sin penetración. La razón subyacente es que se considera más grave que exista un adulto involucrado en la actividad sexual, que el hecho de que la actividad sexual sea o no con penetración. Consideramos que la participación del adulto aumenta el nivel de gravedad, por el abuso de autoridad y vulnerabilidad que implica la diferencia de edad y madurez sexual existente entre ambos.

El Nivel 3 incluye cualquier actividad sexual con penetración de niño a adulto excluyendo dicha actividad cuando es de adulto a niño. Este es un cambio fundamental respecto a la escala SAP que introduce las actividades con penetración (tanto sea de adulto a niño o viceversa). Este cambio supuso un importante debate pero se llegó a la conclusión de que existían diferencias de gravedad dependiendo si el sujeto activo en la actividad con penetración era un adulto o un niño. Si el sujeto activo es un menor consideramos que tenía menor gravedad, puesto que la posición de autoridad y superioridad que representa un adulto como sujeto pasivo es menor que la que ejerce siendo sujeto activo. Por otro lado, las imágenes de penetración de menores hacia adultos son mucho menos frecuentes y, en la mayoría de ocasiones, intermedia un objeto o instrumento sexual.

El Nivel 4 quedaría reservado a las conductas sexuales entre niño y adultos, cuando existe penetración del adulto al niño, donde también se incluye la penetración por vía oral.

El Nivel 5 está reservado a las conductas sexuales más graves, que impliquen dolor o humillación innecesarios, así como el bestialismo o sadismo. Aunque en muchas

investigaciones encaminadas a la iniciación de las investigaciones penales que incluye también las encaminadas a determinar la edad de la víctima, por tanto, aunque se desconozca la edad del menor y haya dudas acerca de su minoría de edad, se continuará con las investigaciones necesarias para la retirada del material, así como de identificación de la víctima. 
ocasiones el dolor real del niño no es apreciable, se consideró oportuno introducir en este nivel aquellas imágenes que muestren dolor o humillación innecesarios.

\subsection{Distribución de la muestra de 4.116 fotografías y de 400 vídeos en los diferentes niveles de la CIESI}

A través del análisis de la muestra de imágenes y videos clasificada, hemos podido llevar a cabo los objetivos secundarios de la investigación, orientados a conocer la naturaleza y niveles de gravedad de las imágenes de pornografía infantil más representativos de la muestra analizada. En el gráfico número 1 presentamos la distribución de la muestra de fotografías, según los niveles de gravedad seleccionados para la clasificación española. En ella podemos observar que la mayor cantidad de material descargado por los usuarios se incluye en el Nivel 1, que corresponde a desnudos y poses eróticas (55\%). A continuación, se encuentran el Nivel 0, que incluye el $13 \%$ de las fotografías descargadas y, el Nivel 3, que incluye el $11 \%$ de las fotografías. Es importante destacar que el $80 \%$ de las fotografías se encuentran clasificadas en niveles leves (del 0 al 2), quedando el 29\% restante en los niveles más graves (3 y 4). Únicamente el 1\% se clasifica en el Nivel 5, de máxima gravedad.

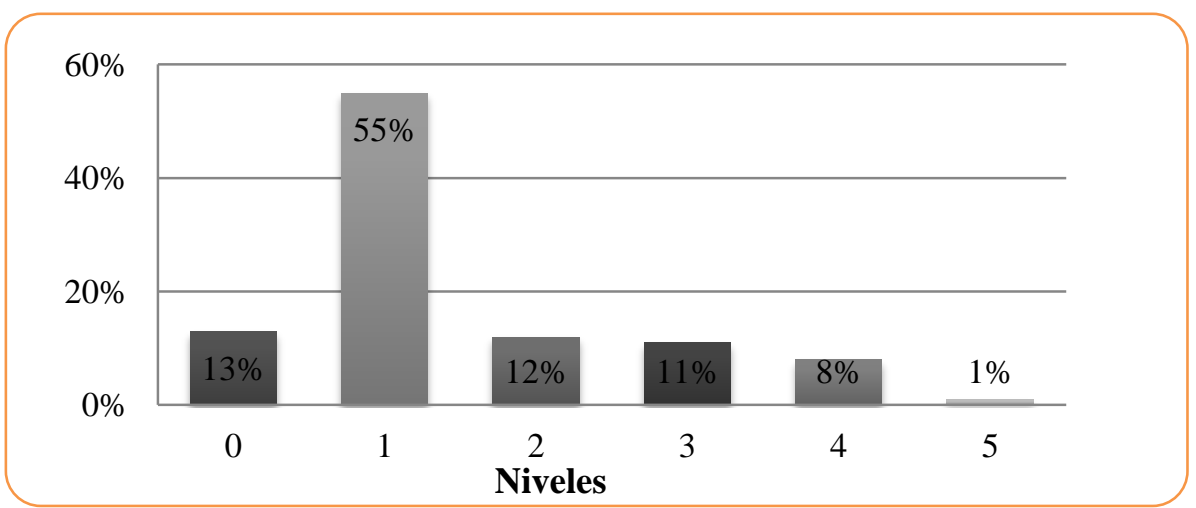

Gráfico 1: Distribución de la muestra de fotografías $(\mathrm{n}=4.116)$ en los niveles de la CIESI

Por el contrario, en el gráfico número 2, se observa la distribución de la muestra de videos en los distintos niveles. En él vemos que, a diferencia de las fotografías, la mayor parte de los videos, se concentran en los niveles superiores, siendo el Nivel 4 el que mayor porcentaje muestra (39\%), seguido del Nivel 2 (21\%), del Nivel 1 (15\%) y, el Nivel $0(7 \%)$ y $5(6 \%)$. 


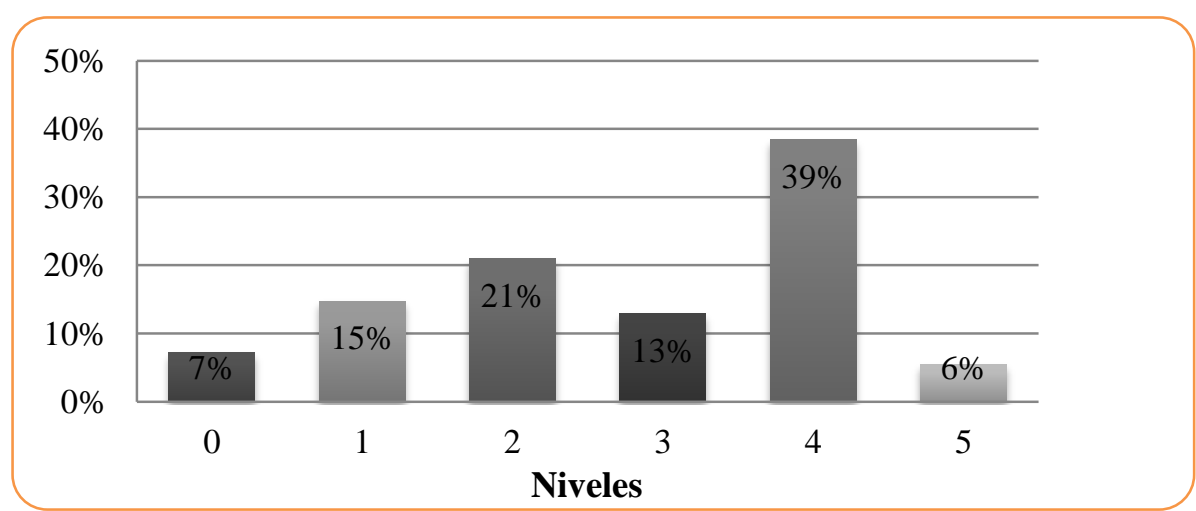

Gráfico 2: Distribución de la muestra de videos $(\mathrm{n}=400)$ en los niveles de la CIESI

La diferencia observada entre fotografías y videos puede deberse a la naturaleza de ambos soportes. Mientras el vídeo es dinámico y sus imágenes pueden clasificarse en diferentes niveles de gravedad incluso hasta el más grave, las fotografías captan momentos específicos y conductas sexuales individuales ${ }^{24}$. Por lo tanto, es normal que se acumulen los videos en los niveles más altos.

\subsection{Distribución de la muestra de videos en función del sexo, etnia y edad de los menores}

El análisis de la muestra según el sexo, la etnia y la edad tenía como finalidad conocer las características más comunes de los menores que se muestran en los videos que, idealmente, correspondería a una mayor preferencia de los usuarios.

En referencia a la edad, existen grandes dificultades para determinar la edad de los menores en las imágenes, por lo que se decidió categorizar en función de la apariencia del menor en la imagen. Realizamos una división en cuatro categorías: a) Bebés para imágenes de bebés de 0 a 2 años; b) Pre-púberes, cuando aparentaban hasta 10 años de edad y, c) Púberes, para aquellos niños o niñas que habían llegado a la pubertad, tomando como referencia las señales físicas ${ }^{25}$. Finalmente, determinamos una categoría indefinida para los casos que, por distintos motivos, era imposible determinar la edad de los menores.

\footnotetext{
${ }^{24}$ Como se ha comentado anteriormente, algunas fotografías de la muestra se organizaban en series fotográficas, mientras que otras eran independientes. Las series fotográficas cuentan una historia y suelen ir en escalada ascendente, de menor a mayor gravedad. Sin embargo, aunque el punto final de una serie fotográfica es el aspecto más importante (Taylor et al., 2001a), para el objetivo principal de la investigación, se atendió a la naturaleza individual de cada imagen para así conocer la variabilidad de conductas que podían incluirse en cada nivel.

${ }^{25}$ La evidencia de vello púbico o desarrollo de senos.
} 
En el gráfico número 3 se presenta la distribución de la muestra en función de las cuatro categorías de edad establecidas. En él vemos que la categoría más frecuente es la de menores pre-púberes (entre 2 y 10 años).

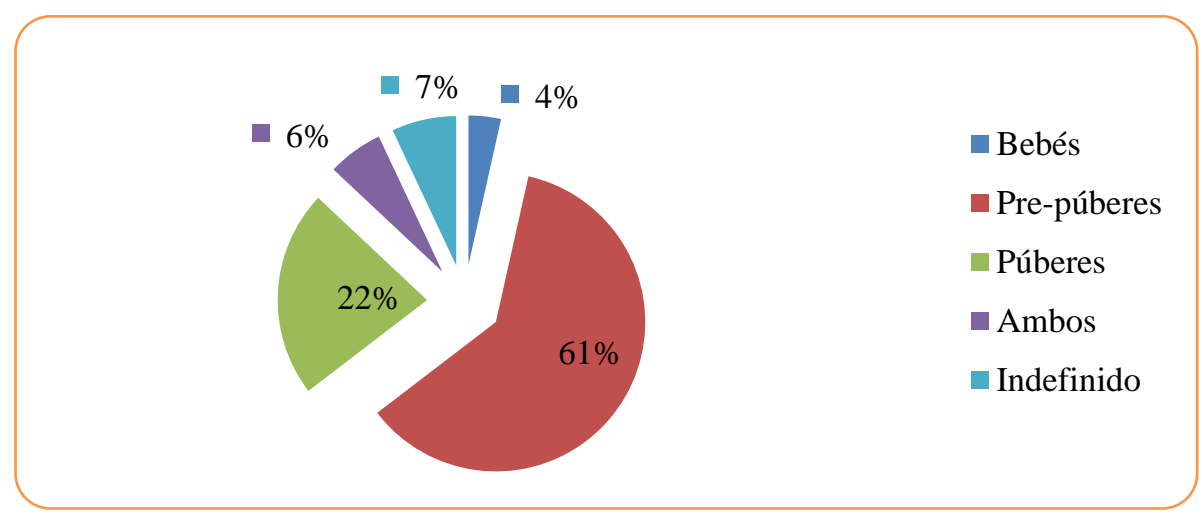

Gráfico 3: Distribución de la muestra de videos $(\mathrm{n}=400)$ respecto a la edad

A continuación, en el gráfico número 4, se muestra la distribución de la muestra de videos en función de la etnia. Esta variable fue dividida en cinco categorías: latina, africana, caucásica, asiática e indefinida, cuando era muy difícil de determinar. Como puede observarse, la etnia caucásica es la más abundante, representando el 78\% de los videos, seguida de la asiática $(9,7 \%)$ y la latina $(5,4 \%)$. En menor proporción están los videos con etnias indefinidas $(4,8 \%)$ o de menores africanos $(1,9 \%)$.

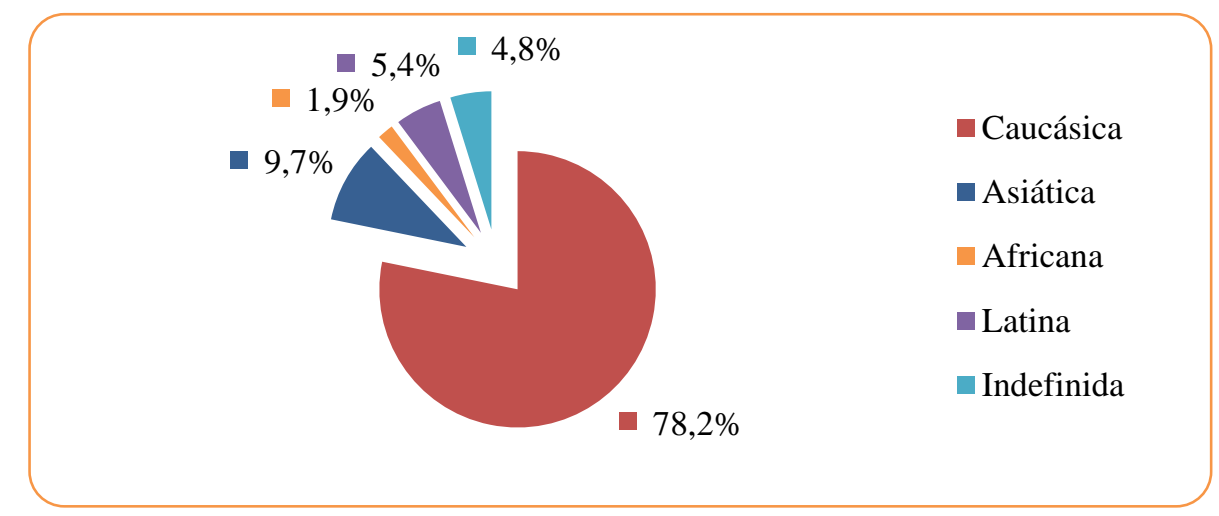

Gráfico 4: Distribución de la muestra de videos respecto a la etnia

Las diferencias de sexo son claramente identificables, tal como vemos en el gráfico número 5 , las preferencias de los usuarios están caramente orientadas hacia el sexo femenino $(77,3 \%)$, siendo inferior la proporción de menores varones $(15,8 \%)$ y muy inferior la existencia de ambos sexos $(5,8 \%)$. 


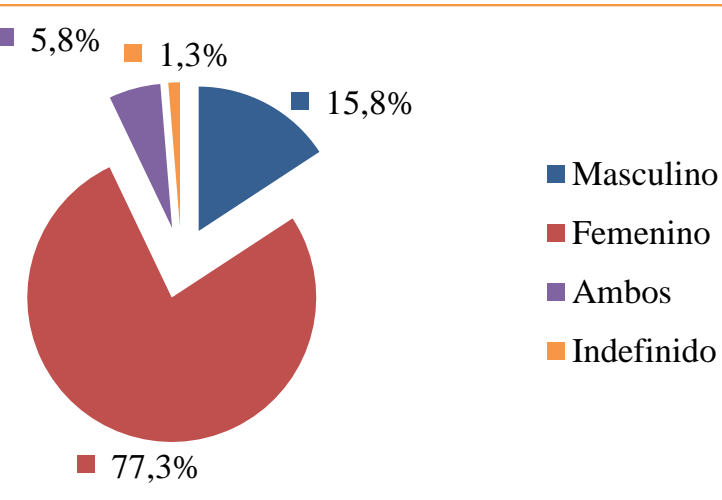

Gráfico 5: Distribución de la muestra de videos $(\mathrm{n}=400)$ respecto al sexo

\subsection{Evaluación interjueces}

Para verificar que efectivamente la clasificación suponía una herramienta útil para clasificar material de imágenes de pornografía infantil, se procedió a su validación mediante un acuerdo interjueces. Dado que varios jueces participaron en la validación, se optó por el estadístico Kappa de Fleiss (Conger, 1980 y Fleiss, 1971).

Para la validación se usó una muestra seleccionada de los 400 vídeos que se usaron inicialmente para desarrollar la clasificación ${ }^{26}$. El cálculo de todos los coeficientes estilo kappa requieren un numero de sujetos denominado $n$, que depende del error relativo $r$ y de la diferencia entre $P_{a}-P_{e}$, donde $P_{a}$, es el acuerdo observado entre los jueces y $P_{e}$ es la probabilidad de acuerdo debido al azar.

La norma propuesta por Gwet ${ }^{27}$ (2010) para seleccionar la muestra mínima necesaria, a priori, supone escoger un margen de acuerdo entre los jueces y luego establecer el margen de error del valor del estadístico Kappa asumible. En nuestro caso, y siendo muy conservadores, escogimos un acuerdo mínimo del $40 \%$ y el mínimo error del 20\%. Por ello, era necesario analizar un mínimo de 156 vídeos. Con el objetivo de ser aún más conservadores y garantizar la representación de todos los niveles, se analizaron 196 videos, 40 más de los estrictamente requeridos. Así, continuando con el objetivo de garantizar una muestra en todos los niveles, se realizó un muestreo aleatorio estratificado de los 400 vídeos empleados para la elaboración de la clasificación de

\footnotetext{
${ }^{26}$ La muestra de fotografías no pudo utilizarse para la validación por razones de acceso, debido a razones policiales no pudo utilizarse para el acuerdo interjueces.

${ }^{27}$ El autor mediante una tabla establece una propuesta de muestra mínima para la validación de estadísticos del tipo kappa (incluido Kappa de Fleiss) en función del error relativo asumido del valor del estadístico y el grado de acuerdo entre los jueces.
} 
acuerdo a:

$$
n_{i}=n \frac{N_{i}}{N}
$$

Como resultado del muestreo aleatorio estratificado, utilizando la función "selección aleatoria" de Excel, se seleccionó el siguiente número de vídeos por nivel: Nivel $0=15$ vídeos; Nivel $1=29$ vídeos; Nivel 2=41 vídeos; Nivel $3=25$ vídeos; Nivel $4=75$ vídeos; Nivel 5= 11 vídeos.

Los 196 vídeos seleccionados se dieron a tres expertos en pornografía infantil de la Guardia Civil que los clasificaron atendiendo a los criterios de la clasificación presentados en este artículo. En ningún caso estos jueces conocían la frecuencia de los vídeos por nivel.

Una vez clasificados los vídeos, se realizaron dos análisis: 1) para comprobar el grado de acuerdo entre los tres expertos en pornografía infantil (jueces B, C y D); y 2) para verificar el acuerdo, incluyendo en los análisis al investigador que en su momento visualizó esos mismos vídeos para realizar la clasificación (juez A).

\subsection{Análisis de datos}

Una vez que los jueces clasificaron los vídeos, se procedió a comprobar el acuerdo interjueces utilizando el estadístico Kappa de Fleiss mediante el programa R.

En primer lugar, se realizaron los análisis con las observaciones de los expertos, los jueces $\mathrm{B}, \mathrm{C}$ y D, dando como resultado un índice de 0,787. Posteriormente, se realizó un nuevo análisis incluyendo al juez $\mathrm{A}$, dando como resultado un índice de 0,802. El acuerdo está, en ambos casos, por encima del planteado a priori (0.400), que sumado a un p-value $<0.05$, el acuerdo resultante es fuerte (Conger, 1980 y Fleiss, 1971), variando ligeramente el resultado cuando introducimos en los análisis al juez A.

\section{Discusión y conclusiones}

\section{1. Discusión}

El estudio expuesto constituye el primer análisis descriptivo de una muestra de fotografías y videos archivados en investigaciones policiales que ha permitido diseñar la primera clasificación de imágenes de pornografía infantil que se presenta en España. 
A través de la metodología empleada se ha podido clasificar el material disponible (dos amplias muestras de fotografías y videos) en 6 niveles de gravedad. Las clasificaciones existentes en otros países (especialmente la SAP) fueron útiles para inspirar la española, si embargo, no se adaptaban completamente al consumo en España y a las necesidades policiales. Por este motivo, se decidió hacer dos cambios respecto a la escala SAP: añadir un nivel 0 para introducir el material donde es imposible establecer la minoría de edad de los menores pero podría conocerse en investigaciones policiales posteriores, e integrar en nieves de gravedad diferentes la actividad sexual con penetración de niño a adulto (Nivel 3) y de adulto a niño (Nivel 4). En este caso, consideramos que dicha distinción se encuentra en coherencia con una mayor gravedad de las imágenes, siendo más grave cuando el sujeto activo de la actividad sexual es un adulto, al mismo tiempo que responde a la necesidad policial en España de orientar las investigaciones hacia las conductas más graves.

De los resultados de nuestra investigación se desprende que el mayor porcentaje de videos descargados se encuentra clasificado en el nivel 4, mientras que las fotografías descargadas se clasifican en el nivel 1. Estas diferencias se deben fundamentalmente a las decisiones metodológicas tomadas en la investigación y a las diferencias de soporte de la imagen. En la actualidad, los estudios en otros países son escasos y no todos muestran resultados en la misma línea. Por un lado, existen dos estudios que presentan resultados similares: Quayle (2009) en su análisis sobre el material incautado en una operación en Gales, clasificó el 91,2\% del material en el Nivel 1 de la clasificación SAP. También Bunzeluk (2009), tras examinar 15.662 webs de 35.111 incidentes denunciados a Cybertip.ca ${ }^{28}$, encontró que el material se concentraba mayoritariamente en el Nivel $1(35,7 \%)$ y en el 3 y $4(33,2 \%)$. En contraste con estos resultados, Niveau (2010), tras analizar una muestra de 36 consumidores de pornografía infantil, encontró que el material consumido se clasificaba entre los niveles 9 y 10 de la escala COPINE (más graves). En la misma línea, Frei y otros (2005), al analizar una muestra de 33 consumidores, advirtieron que el $72 \%$ del material también se encontraba entre los niveles 9 y 10 de la escala COPINE. Dichos resultados muestran resultados dispares que indican la necesidad de seguir investigando para comprender las diferencias.

\footnotetext{
${ }^{28}$ Cybertip.ca se trata de una línea de denuncia de Canadá para informar sobre casos de explotación sexual infantil.
} 
Los resultados descriptivos referentes a los vídeos, presentan ciertas similitudes con trabajos anteriores. Al igual que en nuestra investigación, se advierte la existencia de una mayor frecuencia de imágenes pertenecientes al sexo femenino, de etnia caucásica y de edad pre-púber. La frecuencia de la etnia caucásica podría explicarse por una preferencia de los consumidores de raza blanca por su misma raza (Aiken, Moran y Berry, 2011; Quayle y Jones, 2011; Babchinshin et al., 2011; Seto et al., 2006; Seto et al., 2005) o por la distribución del uso de Internet en la población general, donde la raza blanca se encuentra sobrerrepresentada. Si fuera por esta última razón, un cambio en la distribución por razas de los menores representados en las imágenes de pornografía infantil, podría avanzar una expansión de este mercado a otros segmentos raciales de la población (Babchinshin et al., 2011).

Los estudios en este campo todavía son muy preliminares y no arrojan resultados satisfactorios y concluyentes. Por ello, es necesaria una mayor inversión científica sobre esta materia para seguir avanzando en algunos de los resultados que se han presentado a lo largo del artículo.

\subsection{Limitaciones}

Esta investigación no está exenta de limitaciones. Aunque la mayoría de las imágenes se pueden introducir claramente dentro de los niveles de la CIESI, en algunas ocasiones, los límites entre los niveles pueden estar borrosos. En efecto, el factor decisivo en la clasificación es la intención y el contenido sexual explícito que, en ocasiones, es difícil de identificar o verificar objetivamente (Taylor et al., 2001a).

Por otro lado, aunque el acuerdo entre los jueces es fuerte, se ha apreciado que la diferencia entre los observadores se produce preferentemente en uno de los indicadores más difíciles de objetivar, que es la edad del menor. En la evaluación, los mismos vídeos fueron clasificados en diferentes niveles según la interpretación personal sobre la edad. Los jueces que consideraron que el sujeto tenía mayor de edad, introdujeron el vídeo en el Nivel 0 y los que lo consideraron más joven introdujeron el vídeo en el resto de niveles, según la actividad sexual realizada.

Por otro lado, la evaluación por acuerdo interjueces de la escala solo pudo realizarse con la muestra de vídeos. Ello implica que la clasificación se considera válida para videos y provisional para fotografías. No obstante, cuando el investigador clasifica vídeos se enfrenta a una dificultad que no existe cuando clasifica fotografías: 
seleccionar el comportamiento más grave dentro de múltiples conductas que suceden en el vídeo, frente a la selección de una única conducta que capta la fotografía. Ello, unido a que la evaluación interjueces ha arrojado un fuerte acuerdo en la categorización de los vídeos, podría llevarnos a afirmar que la clasificación también podría ser válida para las fotografías. A pesar de ello, nuevos estudios de validación son necesarios para confirmar la validez de la clasificación, especialmente para las fotografías.

\subsection{Implicaciones prácticas}

Finalmente, a pesar de las limitaciones, las implicaciones prácticas de las clasificaciones de imágenes de pornografía infantil que actualmente existen en Europa son muy relevantes: permiten establecer la gravedad de la infracción en el proceso penal y sirven de apoyo tanto a científicos como a investigadores policiales.

Desde el punto de vista policial, estas escalas constituyen una herramienta que permite priorizar la investigación policial y reorientar los recursos disponibles a la mayor gravedad de los casos. Desde el punto de vista científico, son útiles para profundizar sobre la identidad y características del consumidor de pornografía infantil poniéndolos en relación con el material descargado. La mayoría de las investigaciones que abordan el perfil del consumidor de pornografía infantil apenas tienen en cuenta el contenido del material que los consumidores visualizan.

Teniendo en cuenta la utilidad de las escalas precedentes y los resultados de la investigación presentada (incluyendo la validación por acuerdo interjueces), consideramos que la clasificación española supone un avance para la investigación criminal y policial en España en materia de pornografía infantil, una herramienta válida y confiable de trabajo para clasificar el material de pornografía infantil, así como un punto de partida para futuras líneas de investigación encaminadas a establecer perfiles de consumidores de pornografía que permitan detectar los más vulnerables al abuso sexual infantil.

No obstante, sigue siendo muy necesaria la inversión científica en este campo donde las evidencias empíricas son todavía incipientes y no permiten arrojar conclusiones fuertemente contrastadas. 


\section{Agradecimientos}

Agradecemos la implicación de la Unidad Técnica de Policía Judicial de la Guardia Civil en el desarrollo de esta investigación. Sin su ayuda, dicha clasificación así como su validación no hubiera sido posible.

\section{Referencias}

Aiken, M., Moran, M. y Berry, M.J. (2011). Child abuse material and the Internet: Cyberpsychology of online child related sex offending. 29th meeting of the INTERPOL Specialist Group on Crimes against Children. Lyon, September, 57.

Babchishin, K.M., Hanson, R.K. y Hermann, C.A. (2011). The characteristics of online sex offenders: A meta-analysis. Sexual Abuse: a Journal of Research and Treatment, 23 (1), 92-123.

Bates, A. y Metcalf, C. (2007). A psychometric comparison of internet and non-internet sex offenders from a community treatment sample. Journal of Sexual Aggression, 13 (1), 11-20.

Beech, A.R., Elliott, I.A., Birgden, A. y Findlater, D. (2008). The internet and child sexual offending: A criminological review. Aggression and violent behavior, 13 (3), 216-228.

Bunzeluk, K. (2009). Child sexual abuse images: An analysis of websites by Cybertip. $c a$. Canadian Centre for Child Protection Incorporated. Disponible en https://www.cybertip.ca/pdfs/CTIP ChildSexualAbuse Report en.pdf

Conger, A. J. (1980). Integration and generalization of kappas for multiple raters. Psychological Bulletin, 88 (2), 322-328.

Council of Europe (2014) European Sourcebook of Crime and Criminal Justice Statistics. Fifth Edition. Disponible http://www.heuni.fi/material/attachments/heuni/reports/qrMWoCVTF/HEUNI r eport 80 European_Sourcebook.pdf

Endrass, J., Urbaniok, F., Hammermeister, L.C., Benz, C., Elbert, T., Laubacher, A. y Rossegger, A. (2009). The consumption of Internet child pornography and violent and sex offending. BmC Psychiatry, 9 (1), 9-43.

Fleiss, J.L. (1971). Measuring nominal scale agreement among many raters. Psychological Bulletin, 76 (5), 378-382.

Frei, A., Erenay, N., Dittmann, V. y Graf, M. (2005). Paedophilia on the Internet-a study of 33 convicted offenders in the Canton of Lucerne. Swiss Medical Weekly, 135 (33-34), 488-494.

Gwet, K.L. (2010). Handbook of Inter-Rater Reliability (2nd Edition), Gaithersburg: Advanced Analytics, LLC.

International centre for missing \& exploited children (2012). Child Pornography: Model legislation \& Global Review. Seventh Edition. Disponible en http://www.icmec.org/en_X1/pdf/Child_Pornography_Model_Law_English 7th Edition 2012.pdf

Lanning, K. (1992). Child Molesters: A Behavioural Analysis. Washington DC: National Center for Missing and Exploited Children.

McCarthy, J.A. (2010). Internet sexual activity: A comparison between contact and noncontact child pornography offenders. Journal of Sexual Aggression, 16 (2), 181195. 
Ministerio del Interior (2015). Anuario estadístico. Disponible en http://www.interior.gob.es/documents/642317/1204854/Anuario_estadistico_20 15_126150729.pdf/da61515a-9cd8-4cb4-bdd9-a17f3d3d7b20

Morales, F. (2002). Pornografía infantil e Internet. Jornadas de Responsabilidad Civil y Penal de los Prestadores de Servicios en Internet, Barcelona, 22-23 de Noviembre, 1-13. Disponible en http://www.uoc.edu/in3/dt/20056/index.html

Morillas, D. L. (2005). Análisis dogmático y criminológico de los delitos de pornografía infantil: Especial consideración de las modalidades comisivas relacionadas con Internet. Madrid: Dykinson.

Motivans, M. y Kyckelhahn, T. (2007). Federal prosecution of child sex exploitation offenders. Bureau of Justice Statistics, US Department of Justice.

Niveau, G. (2010). Cyber-pedocriminality: Characteristics of a sample of internet child pornography offenders. Child abuse \& neglect, 34 (8), 570-575.

Orts, E. y Roig, M. (2009). Concepto de material pornográfico en el ámbito penal. ReCRIM: Revista de l'Institut Universitari d'Investigació en Criminologia $i$ Ciències Penals de la UV, (2), 82-139. Disponible en http://www.uv.es/recrim/recrim09/recrim09i01.pdf

Oswell, D. (2006). When images matter: Internet child pornography, forms of observation and an ethics of the virtual. Information, Communication \& Society, 9 (02), 244-265.

Quayle, E. (2008). The COPINE Project. Irish Probation Journal, 5, 65-83.

Quayle, E. (2009). Abuse images of children: identifying gaps in our knowledge. Draft paper for G8 Symposium, UNC, 6-7.

Quayle, E. y Taylor, M. (2001). Child seduction and self-representation on the Internet. CyberPsychology \& Behavior, 4(5), 597-608.

Quayle, E. y Jones, T. (2011). Sexualized Images of Children on the Internet. Sexual Abuse: a Journal of Research and Treatment, 23 (1), 7-21.

Quayle, E. y Taylor. M. (2002). Paedophiles, Pornography and the Internet: Assessment Issues. British Journal of Social Work, 32 (7), 863-875.

Riegel, D.L. (2004). Letter to the Editor: Effects on Boy-Attracted Pedosexual Males of Viewing Boy Erotica. Archives of Sexual Behavior, 33 (4), 321-323.

Seto, M.C., Cantor, J.M. y Blanchard, R. (2006). Child pornography offenses are a valid diagnostic indicator of pedophilia. Journal of Abnormal Psychology, 115 (3), 610.

Seto, M.C. y Eke, A.W. (2005). The criminal histories and later offending of child pornography offenders. Sexual abuse: a journal of research and treatment, 17(2), 201-210.

Seto, M.C., Hanson, R.K. y Babchishin, K.M. (2010). Contact sexual offending by men with online sexual offenses. Sexual abuse: a journal of research and treatment, 23(1) 124-145.

Sotoca, A. (2010). Pornografía Infantil en Internet. Nuevas realidades penales y penitenciarias: los retos en un escenario de Cambios. Actas de las VI Jornadas de ATIP. Almagro, 49-64.

Taylor, M., Holland, G. y Quayle, E. (2001a). Typology of paedophile picture collections. The Police Journal, 74 (2), 97-107.

Taylor, M., Quayle, E. y Holland, G. (2001b). Child pornography, the Internet and offending. ISUMA. The Canadian Journal of Policy research, 2 (2), 94-100.

Warner, K. (2010). Sentencing for child pornography. Australian Law Journal, 84 (6), 384-395. 
Webb, L., Craissati, J. y Keen, S. (2007). Characteristics of Internet child pornography offenders: A comparison with child molesters. Sexual abuse: a journal of research and treatment, 19 (4), 449-465.

Wolak, J., Finkelhor, D. y Mitchell, K. (2009). Trends in arrests of "online predators." Durham, NH: Crimes against Children Research Center.

Wolak, J., Finkelhor, D. y Mitchell, K. (2011). Child pornography possessors: Trends in offender and case characteristics. Sexual abuse: a journal of research and treatment, 23 (1), 22-42

Alejandra Pascual es investigadora del Instituto de Ciencias Forenses y de la Seguridad de la Universidad Autónoma de Madrid.

Andrea Giménez-Salinas Framis es profesora y directora del Área de Ciencias Forenses y Criminológicas en el Instituto de Ciencias Forenses y de la Seguridad en la Universidad Autónoma de Madrid.

Carlos Igual Garrido es Capitán de la Guardia Civil en la Unidad Técnica de Policía Judicial como responsable del Grupo de Delitos contra Mujeres y Menores -EMUME Central. 